\title{
The Sequential Analysis of Transgressors' Accounts of Breaking Environmental Laws
}

\author{
Ana M. Martín, María Esther Salazar-Laplace, and Cristina Ruiz \\ Universidad de La Laguna
}

\begin{abstract}
Three-hundred and twenty written accounts of environmental transgressors were assessed by sequential analysis to reveal their argument streams. The accounts were obtained from the written statements that transgressors are allowed to give during the Spanish administrative process and which were included in files handled by four environmental law enforcement agencies. These agencies are distributed across national, regional, island and municipality jurisdictions. The setting for the study is a highly protected environment in which environmental laws have high salience. Results reveal that transgressors use simple argument streams, consistently more defensive than conciliatory, and questioning the perceived legitimacy of environmental law. It was seen also that the empirical functioning of the explanations related to pursuing emotional/prosocial objectives differs from what was expected from the traditional conceptual definition. Results are discussed in terms of how the assessment of the internal dynamic of the accounts would provide valuable information on transgressors' reasoning in relation to environmental laws.

Keywords: transgressors' accounts, sequential analysis, environmental laws
\end{abstract}

\begin{abstract}
Se examinaron 320 explicaciones exculpatorias dadas por transgresores medioambientales para evaluar, mediante análisis secuencial, sus líneas argumentales. Las explicaciones se obtuvieron a partir de alegaciones que los transgresores pueden presentar por escrito a lo largo del proceso español de sanción administrativa y que estaban incluidas en expedientes tramitados por cuatro administraciones encargadas de aplicar las leyes medioambientales a nivel nacional, autonómico, insular y municipal. El contexto del estudio es un entorno protegido en el que las leyes medioambientales tienen una alta relevancia. Los resultados muestran que los transgresores usan secuencias argumentales simples, consistentemente más defensivas que conciliadoras, y que cuestionan la legitimidad de la ley medioambiental. Se observó también que, empíricamente, las explicaciones relacionadas con la consecución de objetivos emocionales/prosociales funcionan de manera diferente a la esperada según la definición conceptual clásica. Los resultados se discuten enfatizando cómo el análisis de la dinámica interna de las explicaciones proporciona información valiosa acerca del razonamiento de los transgresores respecto a las leyes medioambientales.

Palabras clave: explicaciones de los transgresores, análisis secuencial, leyes medioambientales
\end{abstract}

This research was supported by the Spanish Ministry of Science and Technology, by means of the I+D grant project BSO2002-03255. The article was written while the authors had the I+D grant project SEJ2006-11604/PSIC from the Ministry of Education and Science.

The authors are grateful to the public administrations that collaborated in this study for their inestimable help and to the public enforcement personnel who dedicated part of their work time to make our data collection possible. Thanks also to Vincenç Quera (Universidad de Barcelona) for providing us with valuable material on sequential analysis and to Juan A. Rodríguez (Universidad de La Laguna) for helping us with the statistical analyses.

Correspondence concerning this article should be addressed to Ana M. Martín, Departamento de Psicología Social, Facultad de Psicología. Universidad de La Laguna. Campus de Guajara. 38205- La Laguna (Spain). Phone: 922317518. Fax: 922317461. E-mail: ammartin@ull.es 
Breaches of environmental laws involve actions that harm both the environment and human beings. However, environmental transgressions are not universally perceived as illegal, or even reproachable, as their "wrongness" is not always obvious (Korsell, 2001). This is why, in many cases, society prefers to refer to this type of violations as "accidents" or "human errors" instead of crimes or offences (Mårald, 2001). Indeed, most people have difficulty in distinguishing between legal and illegal anti-ecological behavior, partly because many anti-ecological behaviors become illegal only when they exceed the limits established by the law or when a specific license to carry out an action has not been obtained (Korsell, 2001). Thus, environmental transgression is a rather peculiar form of illegal behavior in its consequences, sanctions, and victims (see Martín, 2005).

The consequences of environmental transgressions are not always immediate or indeed evident, and in some cases even experts disagree in their evaluation of the harm done, depending on whether or not they are involved with the interests of the different parties (Mårald, 2001). Furthermore, as the incident often occurs for the first time, there is frequently no precedent to allow evaluation of the actual situation and predictions of the consequences for the immediate and more distant future. This situation is worse when the punishable effect is not the harm itself but the risk of such harm occurring.

The very severe penalties which do exist for environmental transgression are seldom imposed (Mårald, 2001). This could be because the environmental laws have generally been drawn up in response to extreme, catastrophic events, which are in fact infrequent (Korsell, 2001). Also, as these incidents are perceived as exceptional, the risks of future occurrence and the need for subsequent surveillance are underestimated. Therefore, although the sanctions for those found responsible for ecological disasters are considerable, the infrequency of this type of event makes legal precedents scarce. As a result, prison sentences are very rare, and fines are the most common sanction applied (Korsell, 2001; Watson, 2005). Unfortunately, for corporate transgressors, the fine is minor compared to the routine cost of doing business legally, so it is often more economical to pay the fine (Wilson 1986).

Victims, when compared to those of regular offences, are not specific individuals but are often a large, indeterminate group of people affected in the short or long term. In some cases, environmental transgressions can affect present and future populations and even an entire region. The characteristics of these victims, then, have consequences for the detection of breaches of the law and for public perception of ecological transgressions. As there are no individual victims who feel compelled to report the incident, detection of environmental transgression depends almost exclusively on the efforts of administrations in finding and sanctioning anti-normative behavior.

The profile of the environmental transgressor also contributes to the difficulty in distinguishing between legal and illegal anti-environmental behavior. Corporations, the military, organized crime and even governments have traditionally been blamed for environmental damage (see Situ \& Emmons 2000), but it is more often individuals who are tried by public administrations for acting illegally against the environment, both in personal domains of everyday life and at work (Martín et al., in press). Individual breaches of environmental laws in personal domains of everyday life are not economic crimes or ordinary offences. Furthermore, they are not uniformly a type of anti-social behavior because they do not always harm the resources, well-being and interests of people, nor are they always the result of the human tendency to behave in one's own benefit. On the contrary, given that the motives for individual environmental transgressions can be more a question of commodity and the saving of small amounts of money in personal domains of everyday life (Situ \& Emmons, 2000), they are often not seen as "real" crimes (Situ, 1998).

The above characteristics have contributed to a low perceived legitimacy (Tyler, 1990, 2006) of environmental law that has been demonstrated in studies of accounts by both transgressors and law enforcement personnel. In Situ's (1998) study, transgressors claim that their behavior is not an offence although the law states otherwise. They deny doing harm to anyone and argue that there is no victim involved. In this study, both the transgressors and the officers involved in environmental law enforcement know that the behavior is illegal, but do not understand why. The officers even think that they would be better employed in persecuting perpetrators of "real" crimes. Situ also reports that prosecutors are reluctant to bring criminal charges against environmental offenders. The enforcement personnel believe that the low number of charges was due to the difficulty of establishing criminal intent and because there was no evidence of serious consequences following the environmental misconduct.

This low perceived legitimacy of environmental law by enforcement personnel has also been corroborated in Sweden, in a study by Du Rées (2001). The author interviewed 152 law enforcement officers asking, among other questions, why the supervisory agencies do not report all suspected offences. Their answers were categorized using the Sykes and Matza (1957) neutralization techniques. Most of the enforcement personnel used as justification "Shifting the blame" referring to "the lack of confidence in the capacity of the legal system to deal with the breaches in a satisfactory manner" (p. 120). The enforcement officers felt that most cases would never reach the indictment stage in the criminal system. Also, as in Situ's study, they considered that the breaches had not resulted in direct harm, or that the consequences were not very serious ("Denial of victim/injury"). Lastly, the enforcement officers referred to the need to safeguard "their relationships with the enterprises in question and/or with local authority politicians" (p.121) ("Higher loyalties").

Also using the Sykes and Matza (1957) approach, Eliason and Dodder (1999) carried out a study with 42 
individuals cited for illegal deer possession. Poachers tended to be committed to the dominant normative system of society and believed that illegal deer hunting was wrong. They justify their behavior by neutralization techniques such as denial of responsibility, the metaphor of the ledger, the defense of necessity and condemnation of the condemner, with very negative attitudes towards game wardens.

Although promising, the evidence on accounts of environmental transgressions discussed above has important shortcomings in terms of the samples, conceptual framework and methodology used. In relation to sample limitations, Situ (1998) worked exclusively with transgressions at county level and Du Rées (2001) only with environmental-lawenforcement personnel. Similarly, Eliason and Dodder (1999) constrained their analysis to one type of environmental transgression: poaching.

Secondly, the conceptual framework used to deal with the accounts of environmental transgressions was limited in all the studies to the Sykes and Matza (1957) approach. Sykes and Matza's (1957) neutralization theory explains how individuals who break the law are able to act normatively in other contexts. From their point of view, transgressors use neutralization techniques to make distortions and rationalizations that allow them to reinterpret their behavior as socially acceptable, and even in pro-social terms. In this way, they avoid guilt and protect their self-esteem. Neutralization techniques have received empirical support in relation to embezzlement, delinquency, economic crime, violation of civil rights, police failure to report gender violence incidents and poaching, among other offenses (Maruna \& Copes, 2005; Walters, 2002).

Sykes and Matza (1957) originally described five neutralization techniques: denial of responsibility, denial of injury, denial of the victim, condemnation of the condemner and appeal to higher loyalties (see Maruna \& Copes, 2005; Walters, 2002). Five additional techniques were subsequently added by other authors (see Eliason \& Dodder, 1999; Fritsche, 2002; Maruna \& Copes, 2005): the metaphor of the ledger, defense of necessity, denial of the necessity of the law, the claim that everybody else is doing it, and the claim of entitlement.

But the use of neutralization techniques is not the only way to approach transgressors' accounts of their misconduct in general and accounts of environmental law violations in particular (Fritsche, 2002). It is true that, to our knowledge, no other empirical studies on transgressors' accounts in the environmental domain have been published. However, there has been research on conflictive situations in which a norm has been violated and individuals are asked for the reasons underlying their behavior. According to these studies, transgressor accounts are used in social interaction to reduce conflict (Schönbach, 1990), for self-presentation purposes (McLaughlin, Cody, Dickson, \& Manusov, 1992), and as a way to avoid punishment (Itoi, Ohbuchi, \& Fukuno, 1996).

Most of this research is based on Scott and Lyman's (1968) classic taxonomy on justifications and excuses as means of reducing the attribution of responsibility for wrongdoing. Later, Schönbach (1990) added concessions and refusal to the types of accounts, enlarging the continuum of conflict mitigation-aggravation. Walton (1985) proposed the same four categories, while including and specifying the elements within the categories of justification and excuse. Thus, justifications contain negating the rule, appealing to higher goals, denying damage, and appeals to reciprocity. On the other hand, excuses enclose denying knowledge, denying control and denying intent. The result is a comprehensive coding scheme useful in the classification of judgments of blameworthiness in natural settings.

Lastly, Fritsche (2002) added to Walton's (1985) and Schönbach's (1990) work the new category of "referentialization", as a type of account able to function as an intermediate strategy of interpersonal conflict management. In this case, transgressors neither deny that a specific norm has been violated (justification) nor their connection with the behavior (excuse). They invalidate the opponent's approach without invalidating the opponent's definition of the situation, adding information that was not included in the opponent's reproach and that allows the transgressors to reduce their guilt. This information relates their behavior to another norm, another person or other behavior. The types of accounts included in the category of referentialization are: defense of necessity, appeal of higher loyalties, reference to laziness, reference to the helplessness of the individual, reference to the sins of others, metaphor of the ledger, and promised reform.

As some of the strategies of referentialization were already described by Sykes and Matza (1957), Fritsche's (2002) formulation becomes a comprehensive model able to integrate the research on neutralization techniques and on transgressor accounts in conflict situations and, therefore, useful as a conceptual framework for the present study.

The third shortcoming of previous studies is related to the methodology. The studies of both neutralization techniques and accounts in social conflict interactions described are based on statistical analyses indicating which coding categories are more frequent under certain circumstances or in relation to specific wrongdoing. However, nothing is said about how these categories are hierarchically organized. To go a step further in assessing how transgressors, environmental transgressors in this case, account for their illegal behavior, it is necessary to use a different approach, such as that underlying sequential analysis.

Sequential analysis is a set of statistical techniques useful for studying the dynamic nature of behavioral streams, by detecting behavior patterns and uncovering their temporal structure (Quera \& Bakeman, 2000). By definition, sequential analysis is a useful tool for social scientists interested in the dynamic, process-oriented aspects of behavior, who traditionally have used static statistical procedures which are unable to preserve the sequential information of behavioral data and to show clearly its sequential nature (Bakeman \& Gottman, 1997). 
These techniques have usually been applied to analysis of the observational data obtained in the context of both verbal and non-verbal social interactions (Bakeman, Deckner \& Quera, 2005). It has been proposed (e.g., see Bakeman, 2000; Bakeman \& Gottman, 1997) that when sequential analysis techniques are added to systematic observation, it is possible to capture process aspects of the naturally-occurring behavior observed in naturalistic contexts, something that other measurement procedures have not been able to do. Sequential analysis has been used, for example, for assessing family interactions by Bakeman and Casey (1995), and the engaged behavior of students with disabilities by Logan, Bakeman, and Keefe (1997). More recently, it has been applied also to the study of the influence of peer interaction on spontaneous scientific reasoning by adolescents (Batista \& Rodrigo, 2002), the extent to which typically developing preschoolers were responsive to parental print references during a shared bookreading interaction (Justice, Weber, Ezell, \& Bakeman, 2002), and the physician-patient dialogue surrounding patients' expressions of emotional cues and concerns (Eide, Quera, \& Finset, 2003; Eide, Quera, Graugaard, \& Finset, 2004).

Quera and Bakeman (2000) explicitly state that sequential analysis can also be used to study the development of social skills and play in children, family relationships, interaction in clinical and educational settings, and communication processes. But, as the essential requirement of the technique is that the process under study unfolds in time and can be observed objectively and systematically, other domains such as those that arise from the interface between psychology and law can be included in this list. It is obviously easy to imagine many scenarios in which researchers would like to study the dynamics of the behavioral stream in the legal context. Jury deliberations, eyewitness and/or expert testimony, and legal actor interactions during civil or criminal trials may be only a few of the social interactions where sequential analysis is applicable.

Furthermore, it is possible also to use sequential analysis to study the flow of thinking in written legal texts, such as sentences or written statements by the accused. Although legal texts are not prototypical social interactions, they can be the object of systematic content analysis using a coding schema, and the data obtained in this way can be represented as a sequence of categories (e.g., an event sequence), according to the normalized format required for sequential analysis (Bakeman \& Quera, 1995).

In this context, the purpose of this study is to assess, using sequential analysis, the argument stream of the accounts that environmental transgressors use to avoid public administrations sanctions. These accounts are included in the written statements ("alegaciones" in Spanish) that the accused are allowed by law to submit during the Spanish administrative process. The study setting is a highly protected environment in which environmental law has high salience.

More specifically, we analyzed the nature of these argument sequences in relation to previous studies on accounts of wrongdoing, looking at whether there are one or various argument sequences and how the use of some statements conditions the flow of subsequent utterances. Underlying these objectives is the conviction that analysis of the dynamics of the accounts is needed to better understand the flow of the transgressors' reasoning and that the meaning of a specific explanation may vary, depending on the argument stream in which it is included. Sequential analysis allows this dynamic approach.

We expect that environmental transgressors will be consistent, throughout the argument stream, with the type of explanations they use from the beginning. Once a transgressor initiates an account with a specific type of explanation s/he continues his/her argumentation with the same type. The categories included in each stream will be always of the same type. It is also anticipated that the argument streams will be both defensive and conciliatory, with the former more frequent than the latter, even when environmental safeguards are very important in the study setting. These expectations are based on evidence form previous studies suggesting that environmental law has a low perceived legitimacy.

\section{Method}

\section{Study Setting}

Data were collected on the island of Tenerife, a setting considered especially suitable for the research purposes because it is well-known as a highly-protected environment. $48.6 \%$ of its 2,034 $\mathrm{Km}^{2}$ surface is environmentally protected and includes 43 sites of natural interest with a large number of endemic species of flora and fauna (see http://www.puntoinfo.idecnet.com for more detailed information). Tenerife is the largest of the Canary Islands, one of Spain's 19 autonomous regions, resembling in many aspects the legal and enforcement federated model of many other western countries. Environmental law enforcement agencies in the island are therefore distributed across national, autonomous, island and municipality jurisdictions. For more information on environmental laws and on environment law enforcement agencies in Spain see Parejo-Alfonso (2005) or http://www.mma.es/portal/secciones/normativa/. The same information for the Canary Islands is available at http://www.gobiernodecanarias.org/cmayot/normativa/index.html

\section{Sample}

The sample under study included 320 written statements submitted by the accused during the administrative process aimed at sanctioning their breaches of environmental laws. These statements were obtained from cases tried by the agencies in charge of environmental law enforcement in the island. The majority of these cases were from the regional agency $(62.7 \%)$, followed by the national agency $(17.2 \%)$, the island agency (10.6\%), and the municipal agency $(9.7 \%)$. 
This sample comprised the total number of cases which included written statements, from a larger sample of cases handled by these public administrations during one year (see Martín et al., in press).

The cases refer mainly to illegal construction (45\%), inadequate disposal and/or management of both waste and hazardous materials $(21 \%)$, and illegal use of natural resources and/or non-authorized activities and illegal modification of environmentally protected spaces (9.4\%). The remaining $24 \%$ of the cases related to activities which differ little in their frequency and were, in order: animal abuse, noise, illegal camping, flora, forest fire-starting, environmental impact, fishing and hunting, extractive activities, and emission of smoke/gas/smells.

The most common type of illegal construction is house building, followed by house reform/enlargement, and finally, the building of walls and fences. Common types of waste included construction debris, cars, fuel and oil for vehicles, as well as sewage. Among the most recurrent non-extractive activities are non-authorized breaking-up, removal, clearing and leveling of soil, and driving and parking cars in protected spaces. There are always one or two more frequent examples

Table 1

Definitions and Examples of the Categories (Grouped Into Sets) Used to Code Transgressors' Accounts ACCEPTANCE/ CORRECTION/ COMPENSATION

Reparation measures:

Compensation:

\section{JUSTIFICATION}

Negating the norm:

Denying the damage and/or victim:

Condemning the condemners or appealing to reciprocity:

Emotional/prosocial objectives:

Material/economic objectives:
The individual claims to have repaired the damage caused or violation committed, returning the situation to its original state, or promises to do so. E.g., "I will adapt the building to its surroundings by covering the walls with local stone and planting trees around it."

Positive actions to compensate the damage done or the violation committed. The individual makes reference to their history of positive actions or their good qualities. E.g., "Once the building is completed, public amenities will be created for the urbanized area".

The act is justified by referring to the non-existence of rules about the behavior described, the existence of a social norm which contradicts the legal norm involved, the non-applicability of the norm, the existence of errors in the report or in the presentation of the case, or the existence of incongruent administrative norms. E.g., "Everybody does it".

The act is justified by denying the existence of damage and/or victim(s).E.g., "This does not affect the aesthetic appearance of the building".

The administration is blamed for the act committed, negative attitudes are shown towards the administration or its representatives or the behavior is described as a response to a previous administrative injustice of which the individual was a victim. E.g., "I built it because the municipal council expropriated my house."

The behavior was carried out to achieve an acceptable aim of this type. E.g., "I built it so that my sons/daughters could have their own home."

The behavior was carried out to achieve an acceptable aim of this type. E.g., "I dumped construction debris there to build vegetable gardens".

\section{EXCUSES}

Denying knowledge /

Ignorance of the facts:

Denying intention /

responsibility:

DENIAL

Denial of culpability:

Denying being responsible for the act or having committed the transgression. E.g. "I didn't do it".

Redefining the fact: the Dragon Tree is a protected species."

The transgressor claims to have acted without deliberation or intention, the act is considered accidental or the behavior was the result of forces beyond their control. E.g., "Cetaceans make unpredictable movements; it was them who approached our boat."
Denying knowledge of the law or of the illegality of the behavior. E.g., "I did not know that

Denying having committed the act as described by the authority: claiming that what was done was partially or completely "something else." E.g., "It's not a new building. What I've done is to improve/ embellish/ strengthen/ restore one that already existed." 
of these activities, such as approximation to, persecution and harassment of cetaceans, for animal abuse; the use of illegal procedures and carrying out the activity outside authorized spaces, for fishing and hunting; setting fire to brushwood and stubble, as well as lighting bonfires, for forest fire-starting; and the unauthorized removal of volcanic gravel for extractive activities.

Transgressors were mainly individual (58.8\%), small business (33\%), groups (6.6\%) and public administrations $(1.6 \%)$. But taking into consideration that these businesses are small enterprises (tourist excursion agencies, building, car repairs, etc.) and are mainly local (72.8\%) and regional (12.6\%), their misconduct can also be considered as activities carried out by individuals. In this case, however, these transgressions have to be considered as carried out in the course of a job. The individuals concerned are generally men $(83.5 \%)$, ranging from 21 to 71 years old $(M=45.63$ years, $S D=12.63$ ).

\section{Instruments}

The coding scheme was elaborated using Fritsche's (2002) comprehensive model and Walton's (1985) empirical study and included 11 categories, grouped in four general sets: Acceptance/compensation, Justification, Excuse and Denial. The description of the 11 categories as well as some examples of each is displayed in Table 1.

\section{Procedure}

The data collection procedure was the same in the four administrations. One member of the research team stayed in each administration and was handed the files one by one. She read each file carefully and made a literal transcription of the accounts included in the written statements made by the accused during the administrative process. Later, two trained judges categorized each single meaningful segment or proposition of the accounts, according to the coding schema displayed in Table 1. The inter-coder agreement, measured by Cohen's (1960) Kappa, was 0.87 .

\section{Results}

The sequence of the categories in each case was used as input for the sequential analysis. The length of these sequences varies between 1 and 11 categories, with a median of 2. Therefore, only those sequences with at least two categories were analyzed. The final number of sequences included in the analysis was 197. The distribution of these cases in relation to the type of activity and the type of transgressor did not differ significantly from that described in the sample section.

The sequential analysis carried out was specifically a lagsequential analysis, using the SDIS-GSEQ software (Bakeman
\& Quera, 1995, updated at http://www.gsu.edu/ psyrab/sg.htm or http://www.ub.es/comporta/sg.htm). This software tests whether the probabilities with which categories occur differ from their unconditioned probability (global analysis), in order to see if there are patterns in a given sequence. If this is the case, it is possible to check which preceding categories are responsible for significant changes in the conditioned probability of a target category (residual analysis). The global analysis is carried out using a global test such as Pearson's $\chi^{2}$ for each lag, and the strength of the association between each pair of categories is assessed by sequential indexes as adjusted residuals and Yule's Qs.

The statistical package allows prediction of which category is more likely to be used next when the sequence has started with the category that initiates the allegation. Thus, it is possible to establish links between categories whose transition frequencies are higher than those expected at random. More specifically, it tests whether there is a sequential association pattern between the category that appears immediately after a given category (lag 1), after an intermediate category (lag 2), and so on, until reaching the desired sequence length. This technique is also able to check whether individuals, dyads or groups with different characteristics display different sequential patterns or whether these patterns vary depending on situations or times. However, category sequences longer than those found in the written statements studied here are necessary to be able to use subsequent conventional statistical tests to make these contrasts (Quera \& Bakeman, 2000).

In the present study, given the reduced length of the accounts, only the five most frequently used categories were included in the analyses and no more than two lags were assessed. The most frequent categories were: Negating the norm (35.83\%), Reparation measures (14.23\%), Redefining the fact $(10.31 \%)$, Denying intention/responsibility (7.98\%), and Emotional/prosocial objectives (7.73\%). The transition frequencies of these categories, for lag 1 and lag 2, are displayed in Table 2. Thus, although 197 sequences (those with 2 or more categories) were included in the analysis, the size of the sample for the analysis is the number of transitions between pairs of categories, which is 311 in lag 1 and 180 in lag 2.

Results show that there is a significant global association between the first and the second categories (lag 1), $\chi^{2}(16$, $N=311)=78.15, p<.05$, and between the first and the third (lag 2), $\chi^{2}(16, N=180)=28.08, p<.05$. The probability of occurrence of these five categories conditioned to the category criterion was also calculated for lag 1 and lag 2 by adjusted residuals ( $z$ values) and Yule's $Q$. Note that adjusted residuals indicate only that there is a significant sequential pattern of activation when adjusted residuals are higher than +1.96 or a significant sequential pattern of inhibition when adjusted residuals are lower than $-1.96(p$ $<.05)$. The adjusted residuals depend on the transition frequencies, so the more transitions, the higher the residuals 
Table 2

Frequencies of Transition for the Five Most Frequent Categories in Lags 1 and 2 Resulting from the Lag Sequential Analysis

\begin{tabular}{|c|c|c|c|c|c|c|c|c|c|c|c|c|}
\hline & \multicolumn{6}{|c|}{ Lag 1} & \multicolumn{6}{|c|}{ Lag 2} \\
\hline & $\mathrm{Nn}$ & $\mathrm{Rm}$ & $\mathrm{Rf}$ & Di & Epo & Total & $\mathrm{Nn}$ & $\mathrm{Rm}$ & $\mathrm{Rf}$ & Di & Epo & Total \\
\hline Negating the norm $(\mathrm{Nn})$ & 113 & 33 & 15 & 6 & 9 & 176 & 65 & 16 & 2 & 13 & 13 & 109 \\
\hline Reparation measures (Rm) & 12 & 16 & 1 & 3 & 4 & 36 & 5 & 6 & 0 & 1 & 2 & 14 \\
\hline Redefining the fact (Rf) & 13 & 5 & 8 & 6 & 2 & 34 & 10 & 3 & 3 & 4 & 1 & 21 \\
\hline Denying intention (Di) & 6 & 9 & 1 & 5 & 7 & 28 & 6 & 3 & 1 & 4 & 0 & 14 \\
\hline Emotional/prosocial objectives (Epo) & 9 & 11 & 1 & 8 & 8 & 37 & 7 & 4 & 2 & 3 & 6 & 22 \\
\hline Total & 153 & 74 & 26 & 28 & 30 & 311 & 93 & 32 & 8 & 25 & 22 & 180 \\
\hline
\end{tabular}

significance. The Yule's $Q$ interpretation, on the contrary, does not depend on the number of transitions, making it more appropriate for comparisons between the same pair of categories observed in samples of different size. Yule's $Q$ s show the strength of the sequential association between two given categories, from -1 , when the relation is negative and perfect, to +1 , when the relation is positive and perfect. Yule's $Q$ is equal to 0 when there is no relation between categories.

Table 3 shows the statistically significant values for adjusted residuals and Yule's $Q$ in each of the five most frequent categories, in lag 1 and lag 2. On the one hand, activation patterns (positive adjusted residuals) show that, when transgressors initiate an account with a specific category, most of the time they continue with the same type of argument (activation patterns), except in the cases of Denying intention/responsibility and Emotional/prosocial objectives. Emotional/prosocial objectives is followed, not only by itself, but by Denying intention/responsibility, whereas Denying intention/responsibility is the only case in which the category which follows is a different one: Emotional/prosocial. On the other hand, inhibition patterns (negative adjusted residuals) show that avoided categories are different, depending on the category which initiates the stream. The strength of the associations between categories (Yule's $Q$ s) varies both in activation and inhibitions patterns. For example, the strongest positive association is that between Redefining the fact and Redefining the fact, in lag 2 (.67), whereas the strongest negative association is that between Norm negation and Denying intention/responsibility, in lag 1 (-.69).

The nature of the argument streams can be more clearly observed by looking at Figure 1 where the category sequences can be differentiated as more defensive and

Table 3

Adjusted Residuals and Yule's Qs for the Five Most Frequent Categories in Lags 1 and 2 Resulting from the Lag Sequential Analysis Conditional Categories

\begin{tabular}{|c|c|c|c|c|c|c|}
\hline \multirow[b]{3}{*}{ Category } & \multicolumn{6}{|c|}{ Conditional Categories } \\
\hline & \multicolumn{3}{|c|}{$\begin{array}{c}\text { Lag } 1 \\
\left(\chi^{2}(16, N=311)=78.15, p=.000\right)\end{array}$} & \multicolumn{3}{|c|}{$\begin{array}{c}\text { Lag } 2 \\
\left(\chi^{2}(16, N=180)=28.08, p=.03\right)\end{array}$} \\
\hline & Category & AdjustedResiduals & Yule's $Q$ & Category & AdjustedResiduals & Yule's $Q$ \\
\hline \multirow[t]{4}{*}{ 1. Negating the norm: $(\mathrm{Nn})$} & $\mathrm{Nn}$ & 6.04 & .62 & $\mathrm{Nn}$ & 2.65 & .39 \\
\hline & $\mathrm{Di}$ & -3.94 & -.69 & $\mathrm{Rf}$ & -2.11 & -.66 \\
\hline & Epo & -3.09 & -.55 & & & \\
\hline & $\mathrm{Rm}$ & -2.39 & -.31 & & & \\
\hline \multirow[t]{2}{*}{ 2. Reparation measures: $(\mathrm{Rm})$} & $\mathrm{Rm}$ & 3.09 & .50 & $\mathrm{Rm}$ & 2.56 & .60 \\
\hline & $\mathrm{Nn}$ & -2.02 & -.36 & & & \\
\hline 3. Redefining the fact: (Rf) & $\mathrm{Rf}$ & 3.39 & .63 & $\mathrm{Rf}$ & 2.33 & .67 \\
\hline \multirow[t]{2}{*}{ 4. Denying intention: (Di) } & Epo & 2.88 & .58 & & & \\
\hline & $\mathrm{Nn}$ & -3.08 & -.60 & & & \\
\hline \multirow[t]{3}{*}{ 5. Emotional/prosocial objectives: (Epo) } & $\mathrm{Di}$ & 2.86 & .56 & Epo & 2.30 & .54 \\
\hline & Epo & 2.63 & .52 & $\mathrm{Nn}$ & -1.99 & -.44 \\
\hline & $\mathrm{Nn}$ & -3.22 & -.55 & & & \\
\hline
\end{tabular}


more conciliatory streams. Argument streams initiated by categories such as Negating the norm or Redefining the fact are considered more defensive, as essentially oriented to the avoidance of punishment. Argument streams initiated by categories such as Reparation measures, Denying intention/responsibility, or Emotional/prosocial objectives are considered more conciliatory, to the extent that they seem to try to avoid not only punishment, but interpersonal conflict, by providing a more positive self-presentation. A closer look at the pattern of inhibition for the defensive sequence suggests that when the sequence starts with Negating the norm it is not likely that categories such as Denying intention/responsibility, Emotional/prosocial objectives, Reparation measures, or Redefining the fact (in lag 2) are used later on as arguments. Likewise, when Reparation measures, Denying intention/responsibility, or Emotional/prosocial objectives appear first, Negating the norm is not likely to be used to justify the reported behavior.

\section{Defensive arguments streams}
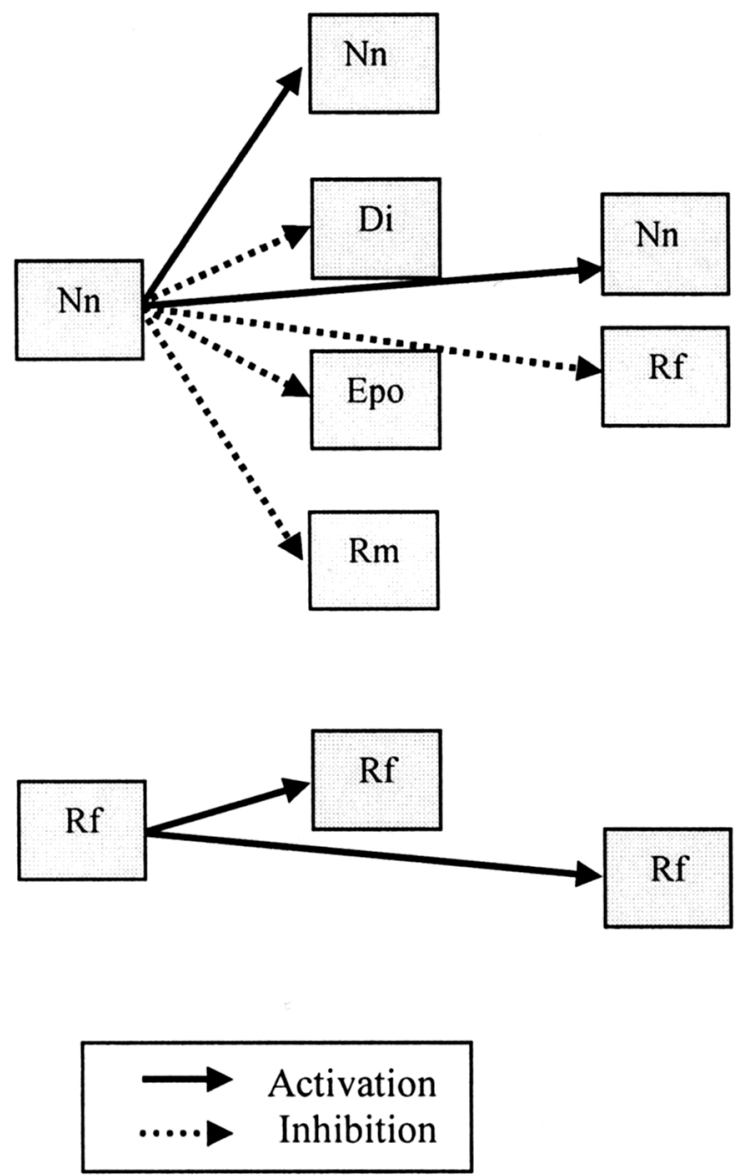

Discussion

The first result in the present study shows, as in Situ (1998), Du Rées (2001) and Eliason and Dodder (1999), that environmental transgressors declare that what they have done is not wrong. This is rather obvious, given the context of avoiding punishment in which such a declaration is made. What is interesting, however, is that transgressors justify their behavior by referring to the non-existence of laws about the behavior described, the non-applicability of the norm, the existence of errors in the report or in the presentation of the case, the existence of incongruent administrative norms and, especially, the existence of a social norm which contradicts the legal norm involved. The expression most used was "Everybody does it!".

What this study adds to previous findings is that transgressors are using simple argument streams, composed of few and similar explanations, as if they were not very worried about avoiding punishment. And this happens even
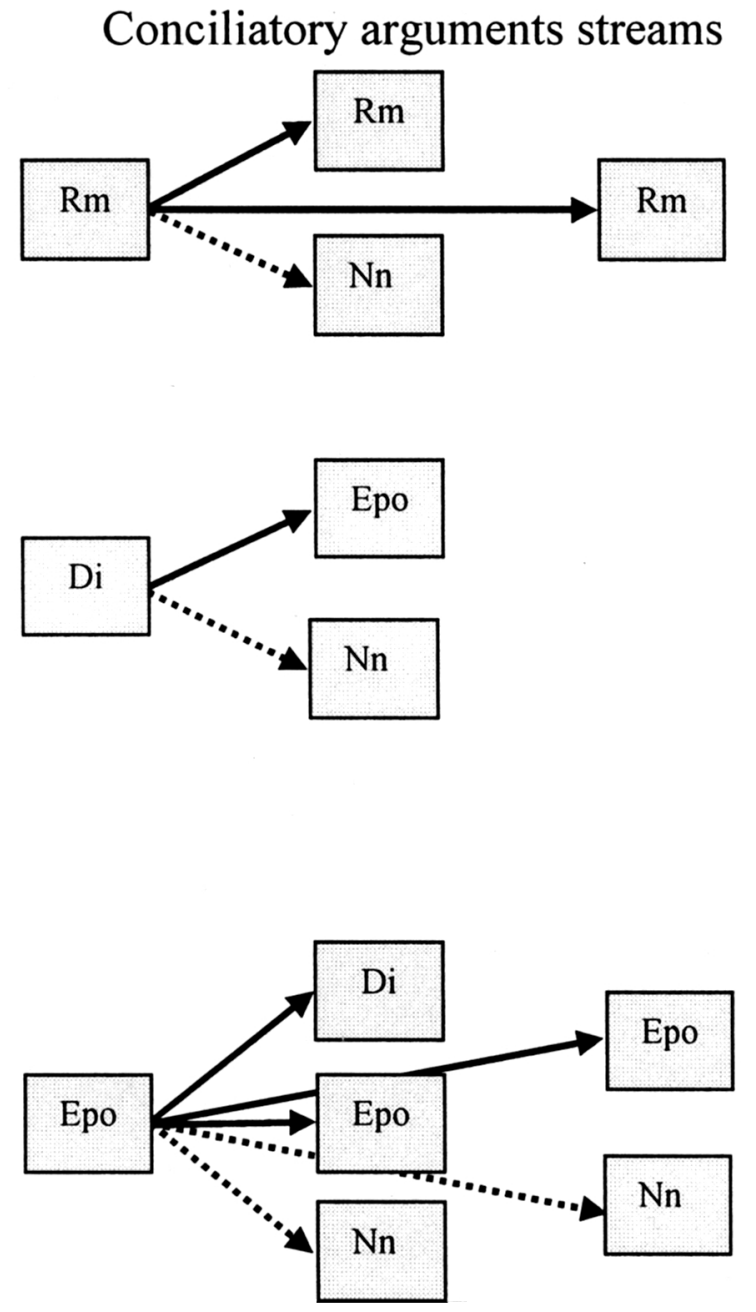

Figure 1. Argument streams in transgressors' accounts 
when environmental safeguards are highly important. The question is whether this happens because the transgressions they are accounting for are environmental or just because are transgressions. The data analyzed in the present study are from the cases included in the files from administrations dealing only with environmental transgressions. Therefore, comparable data on other types of transgressions are not available. Comparisons between our results and those from previous studies on non-environmental transgressions are possible, but only in relation to the content of the accounts because, to our knowledge, no previous studies on the dynamics of the accounts have been carried out.

Our results are also very close to Walton's (1985) and Schönbach's (1992) in a similar context of punishment avoidance, because the categories most used are, in relation to the sets, Justification, Denial, Acceptance, Excuse and, again, Justification. However, there are two differences that require explanation. The first difference is that, in contrast to Waltons's (1985) results, in the present study a category related to Justification is less frequent than one of Excuse. To address this difference it is necessary to consider the conceptual structure of the accounts as reflected by the sequential analysis.

The use of sequential analysis allows us to see that when environmental transgressors initiate an account with an explanation from a specific category, they continue with the same type of explanation (Acceptance, Justification, Excuse or Denial), either developing a more defensive or more conciliatory stream of arguments. This happens except when transgressors use the category Emotional/prosocial objectives. This category is the only one which appears positively related to a category different from itself. Emotional/prosocial objectives is a category related to the set of Justification in conceptual terms but, in this particular situation, it seems to follow a pattern of Excuse. If we look at the categories which initiate the streams in terms of sets, each category is always followed by the same type of category, for example, a Justification is always followed by another Justification and never by an Acceptance, Denial or Excuse. However, Emotional/Prosocial objectives, which is a Justification, is never followed by another Justification, but by Denying intention/responsibility, which is an Excuse.

This result seems to suggest that the explanations included in the account may function differently depending on the dynamics of the streams in which they are included. What we do not know is whether this dynamic nature is specific for environmental-transgressors' accounts, is shared by other types of transgressors' accounts or is a common feature of any account of wrongdoing. To investigate these alternatives, more research comparing different types of transgressors' accounts is needed.

It may also be that appealing to Emotional/prosocial objective were neither a Justification nor an Excuse, but a "Referentialization", as defined by Fritsche (2002). If this were the case, transgressors were not using this intermediate category as a strategy to either deny that a specific norm has been violated (Justification) or their connection with the behavior (Excuse). Transgressors would be able in this way to manage interpersonal conflict by invalidating the authorities' approach without invalidating the authorities' definition of the situation. Their accounts would provide information that was not included in the authorities' claim and that would allow transgressors to reduce their guilt. Looking at the type of accounts included in this set by Fritsche (2002), both the defense of necessity and the appeal of higher loyalties may be easily considered as Emotional/relational objectives, as well as the reference to the helplessness of the individual. It seems that what transgressors are doing when using this category is referring to other norms, persons, or behaviors. For example, to avoid a sanction for illegal construction, a man says that he built a house so his daughter could have her own home. In doing so he is trying to change the authorities' focus of attention from him carrying out an illegal behavior to his daughter getting a home. He has changed person, behavior, and norm in the same account.

The second difference between our results and Walton's (1985) is that in the latter study, the category of Acceptance is more used than those of Justification and Denial, the opposite of what happens here and of what Schönbach (1992) suggests. To explain this difference it is necessary to take into account that we are comparing young children (from kindergarten to fourth grade) to grown adults (from 21 to 71 years old). It is not surprising that to accept wrongdoing is easier for a child in a classroom than for a person being charged with breaking the law, even laws perceived as of low legitimacy. The results described here fit, therefore, more with Schönbach's (1992) than with Walton's (1985), to the extent that the latter considers that for serious misconduct, people use more defensive than conciliatory streams, with Justification and Denial being defensive streams and Acceptance and Excuses conciliatory streams.

Summing up, it seems that transgressors' accounts of breaking environmental law have specific content related to a questioning of environmental law, but that the conceptual nature of the argument streams accords with those of avoiding punishment for serious misconduct. What is still unknown is whether the internal dynamics of these accounts is specific to environmental transgression and/or whether this may vary depending on the characteristics of the transgressor or transgression. The characteristics of the data analyzed in the present study do not allow such contrasts. It is likely, however, that when sequential analysis is used with accounts occurring in verbal social interactions or with longer written legal statements, differential patterns of transgressors' accounts of breaking environmental laws will be revealed. This study is a beginning in the assessment of the content and dynamics of transgressors' reasoning with regard to breaking environmental laws. 


\section{References}

Bakeman, R. (2000). Behavioral observation and coding. In H.T. Reis \& C.K. Judd (Eds.), Handbook of research methods in social psychology (pp. 138-159). New York: Cambridge University Press.

Bakeman, R., \& Casey, R.L. (1995). Analyzing family interaction: Taking time into account. Journal of Family Psychology, 9, 131-143.

Bakeman, R., Deckner, D., \& Quera, V. (2005). Analysis of behavioral streams. In D.M. Teti (Ed.), Handbook of research methods in developmental science (pp. 494-420). Oxford, UK: Blackwell.

Bakeman, R., \& Gottman, J.M. (1997). Observing interaction: An introduction to sequential analysis ( $2^{\text {nd }}$ ed.). New York: Cambridge University Press.

Bakeman, R., \& Quera, V. (1995). Analyzing interaction: Sequential analysis with SDIS and GSEQ. New York: Cambridge University Press.

Batista, L.M., \& Rodrigo, M.J. (2002). ¿Es el conflicto cognitivo el único beneficio de la interacción entre iguales? Infancia y Aprendizaje, 25, 69-84.

Cohen, J.A. (1960). A coefficient of agreement for nominal scales. Educational and Psychological Measurement, 20, 37-46.

Du Rées, E. (2001). Can criminal law protect the environment? Journal of Scandinavian Studies in Criminology and Crime prevention, 2, 109-126.

Eide, H., Quera, V., \& Finset, A. (2003). Exploring rare patient behaviour with sequential analysis: An illustration. Epidemiologia e Psichiatria Sociale, 12, 109-114.

Eide, H., Quera, V., Graugaard, P., \& Finset, A. (2004). Physicianpatient dialogue surrounding patients' expression of concern: Applying sequence analysis to RIAS. Social Science \& Medicine, 59, 145-155.

Eliason, S.L., \& Dodder, R.A. (1999). Techniques of neutralization used by deer poachers in the western United States: A research note. Deviant Behavior, 20, 233-252.

Fritsche, I. (2002). Account strategies for the violation of social norms: Integration and extension of sociological and social psychological typologies. Journal for the Theory of Social Behavior, 32, 21-83.

Itoi, R., Ohbuchi, K.I., \& Fukuno, M. (1996). A cross-cultural study of preference of account: Relationship closeness, harm severity, and motives of account making. Journal of Applied Social Psychology, 26, 913-934.

Justice, L.M., Weber, S.E., Ezell, H.K., \& Bakeman, R. (2002). A sequential analysis of children's responsiveness to parental print reference during shared book-reading interactions. American Journal of Speech-Language Pathology, 11, 30-40.

Korsell, L.E. (2001): Big stick, little stick: Strategies for controlling and combating environmental crime. Journal of Scandinavian Studies in Criminology and Crime Prevention, 2, 127-148.

Logan, K.R., Bakeman, R., \& Keefe, E.B. (1997). Effects of instructional variables on the engaged behavior of students with moderate, severe, and profound disabilities in general education elementary classrooms. Exceptional Children, 63, 481-497.
Mårald, E. (2001): The BT Kemi scandal and the establishment of the environmental crime concept. Journal of Scandinavian Studies in Criminology and Crime Prevention, 2, 149-170.

Martín, A.M. (2005). Aportaciones de la psicología jurídica al control y prevención de los delitos ecológicos. In R. Arce, F., Fariña, \& M. Novo, M. (Comps.), Psicología jurídica (pp. 6171). Santiago de Compostela, Spain: Xunta de Galicia.

Martín, A.M., Salazar-Laplace, M.E., Hess, S., Ruiz, C., Kaplan, M.F., Hernández, B., \& Suárez, E. (in press). Individual breaches of environmental laws in cases from Public Administration files. Deviant Behavior.

Maruna, S., \& Copes, J. (2005). What have we learned from five decades of neutralization research? Crime and Justice: An Annual Review of Research, 32, 221-320.

McLaughlin, M.L, Cody, M.J., Dickson, R., \& Manusov, V. (1992). Accounting for failure to follow advice: Real reasons versus good explanations. In M.L. McLaughlin, M.J. Cody, \& S.J. Read (Eds.), Explaining one's self to others: Reason giving in a social context. (pp. 281-294). Hillsdale: Erlbaum.

Parejo-Alfonso, L. (2005). Código de Medio Ambiente. Cizur Menor (Spain): Aranzadi.

Quera, V., \& Bakeman, R. (2000). Quantification strategies in behavioral observation research. In T. Thomson, D. Felce, \& F. Symons (Eds.), Behavioral observation: Technology and applications in developmental disabilities (pp. 297-315). Baltimore: Brookes.

Schönbach, P. (1990). Account episodes. The management of escalation of conflict. Cambridge, UK: Cambridge University Press.

Scott, M.B., \& Lyman, S.M. (1968). Accounts. American Sociological Review, 33, 46-62.

Situ, Y. (1998). Public transgression of environmental law: a preliminary study. Deviant Behavior: An Interdisciplinary Journal, 19, 137-155.

Situ, Y., \& Emmons, D (2000): Environmental crime. The criminal justice system's role in protecting the environment. Thousand Oaks, CA: Sage.

Sykes, G.M., \& Matza, D. (1957). Techniques of neutralization: A theory of delinquency. American Sociological Review, 43, 643-656.

Tyler, T.R. (1990). Why people obey the law. New Haven, CT: Yale University Press.

Tyler, T.R. (2006). Psychological perspectives on legitimacy and legitimation. Annual Review of Psychology, 57, 375-400.

Walters, G.D. (2002). Criminal belief systems: An integratedinteractive theory of lifestyles. Westport: Praeger.

Walton, M.D. (1985). Negotiation of responsibility: Judgments of blameworthiness in a natural setting. Developmental Psychology, 21, 725-736.

Watson, M. (2005). Environmental offences: The reality of environmental crime. Environmental Law Review, 7, 190-200.

Wilson, J.D. (1986). Re-thinking penalties for corporate environmental offenders: A view of the law reform commission of Canada's sentencing in environmental cases. McGill Law Journal, 30, 315-332.

Received February, 22, 2007

Revision received June, 14, 2007 Accepted July, 11, 2007 